\title{
Studies on the Temperature of the Gastrointestinal Tract
}

\author{
Seventh Report \\ Response of the Intragastric Temperature to Histamine \\ By \\ Hisayuki Masuda \\ (增田久之) \\ From the Medical Clinic of Prof. T. Kurokawa, \\ Tohoku University, Sendai
}

(Received for publication, September 4, 1952)

Response of the intragastric temperature of healthy men, especially young adults, to histamine was reported previously ${ }^{12}$ in comparison with other various drugs. In this report, a further study is presented selecting not only healthy men but also patients with several diseases of the digestive system, and men of various age groups.

\section{EXPERIMENTAL}

\section{Methods and Materials}

The intragastric temperature was measured simultaneously with the pulse rate, blood pressure and gastric juice after the same procedures as previously reported"). 1:1000 solution of histamine hydrochloride was subcutaneously injected in a dose from 0.0093 to $0.0200 \mathrm{mg}$. per $\mathrm{kg}$. to 100 individuals who are listed in Table I. The room temperature ranged between 11 and $24^{\circ} \mathrm{C}$.

\section{Results}

The data of the changes in the intragastric temperature after the injection of histamine are given in Tables II and III, with the maximums, minimums and means of the injected dose, room temperature, age of the men tested and intragastric temperature before the injection. In Table II the changes in the case in which the materials are classified according to their diseases including healthy state and in Table III those classified according to their ages are illustrated, showing only the upper and lower limits and means of the changes at each time. Plotting the means in Tables II and III, respectively Figures 1 and 2 are obtained. The means of the changes in the pulse rate, diastolic blood pressure and 
TABLE I

Age and Disease or State of 100 Individuals Tested

\begin{tabular}{|c|c|c|c|c|c|c|c|}
\hline \multirow{2}{*}{$\frac{\text { Age group }}{15-20 \text { years }}$} & \multirow{2}{*}{\begin{tabular}{c} 
Sex \\
\multirow{8}{*}{} \\
क
\end{tabular}} & \multicolumn{2}{|c|}{ Number } & \multirow{2}{*}{$\begin{array}{l}\text { Disease or state } \\
\text { Healthy state }\end{array}$} & \multirow{2}{*}{$\frac{\text { Sex }}{\stackrel{8}{8}}$} & \multicolumn{2}{|c|}{ Number } \\
\hline & & $\begin{array}{l}3 \\
3\end{array}$ & 6 & & & $\begin{array}{r}18 \\
8\end{array}$ & 26 \\
\hline $20-29$ years & $\stackrel{8}{8}$ & $\begin{array}{r}16 \\
1\end{array}$ & 17 & Gastric ulcer & $\begin{array}{l}\hat{0} \\
\stackrel{+}{0}\end{array}$ & $\begin{array}{r}10 \\
2\end{array}$ & 12 \\
\hline $30-39$ years & $\begin{array}{l}\text { 오 } \\
\text { 우 }\end{array}$ & $\begin{array}{l}9 \\
7\end{array}$ & 16 & Duodenal ulcer & $\begin{array}{l}\hat{0} \\
\text { 우 }\end{array}$ & $\begin{array}{l}9 \\
0\end{array}$ & $\mathbf{9}$ \\
\hline $40-49$ years & $\begin{array}{l}\hat{0} \\
\stackrel{q}{q}\end{array}$ & $\begin{array}{r}20 \\
5\end{array}$ & 25 & Gastric cancer & $\begin{array}{l}\hat{\delta} \\
+\end{array}$ & $\begin{array}{l}22 \\
10\end{array}$ & 32 \\
\hline $50-59$ years & $\begin{array}{l}\hat{0} \\
\text { + }\end{array}$ & $\begin{array}{l}20 \\
10\end{array}$ & 30 & Cholelithiasis & $\begin{array}{l}\hat{0} \\
\stackrel{+}{+}\end{array}$ & $\begin{array}{l}8 \\
6\end{array}$ & 14 \\
\hline $60-70$ years & $\begin{array}{l}\text { ㅇ } \\
\text { + }\end{array}$ & $\begin{array}{l}4 \\
2\end{array}$ & 6 & Gastrectomized state & $\begin{array}{l}\text { \$ } \\
\text { 우 }\end{array}$ & $\begin{array}{l}5 \\
2\end{array}$ & 7 \\
\hline $15-70$ years & $\begin{array}{l}\hat{\delta} \\
\stackrel{+}{2}\end{array}$ & $\begin{array}{l}72 \\
28\end{array}$ & 100 & Total & $\begin{array}{l}\hat{0} \\
\stackrel{+}{q}\end{array}$ & $\begin{array}{l}72 \\
28\end{array}$ & 100 \\
\hline
\end{tabular}

gastric free acidity are illustrated in Figures 3 and 4.

\section{Discussion}

At first the general views of the changes after the injection of histamine are given. Immediately following the injection, a flush of the face, heat sensation and palpitation were observed simultaneously with increases in the pulse rate and pulse pressure, and a drop in the diastolic blood pressure. The systolic blood pressure was also lowered, but the drop was smaller and variable by individuals. In succession to those changes, the intragastric temperature began to fall. The pulse rate reached the maximum increase of 16.4 per minute on an average, in the course of the first 10 minutes and thereafter it began to diminish recovering at 30 minutes after the injection (Fig. 3). About the same time the flush of the face and the palpitation gradually disappeared and cold sensation began to appear. The diastolic blood pressure reached the maximum drop of $-22.2 \mathrm{~mm} . \mathrm{Hg}$ at 10 minutes after the injection and recovered by 60 minutes (Fig. 3). In most cases the maximum drop of $-0.20--0.50^{\circ} \mathrm{C}$ of the intragastric temperature was observed at 15-20 minutes after the injection. The onset of the drop was somewhat later than those of the changes in the pulse rate and blood pressure. It recovered at about 60 minutes after the injection and its recovery was also later than those of the pulse rate and blood pressure (Fig. 1). The flush of the face, the heat sensation, the drop in the diastolic blood pressure and the increase 
Gastrointestinal . Temperature. VII

\begin{tabular}{|c|c|c|c|c|c|c|c|c|}
\hline \multirow{14}{*}{ 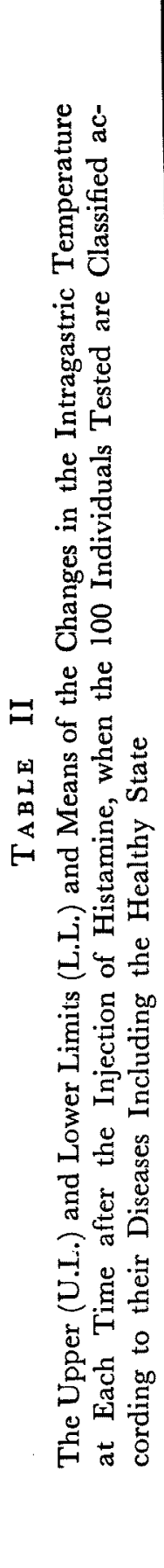 } & 80 & 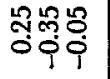 & 융ㅁㅇ & ợ: & 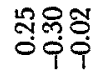 & 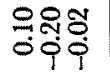 & 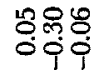 & 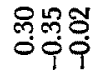 \\
\hline & Oית & 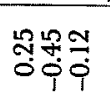 & ఫิণ్యిర్ధి & 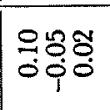 & 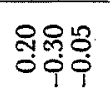 & 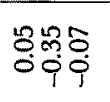 & 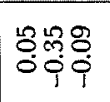 & $\begin{array}{l}489 \\
09 \\
09\end{array}$ \\
\hline & 망 & 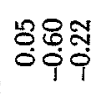 & 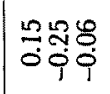 & $\mid \begin{array}{l}\text { ong } \\
\text { opiofi }\end{array}$ & nop & 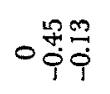 & 苂昂: & $\begin{array}{l}n 80 \\
3090\end{array}$ \\
\hline & 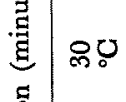 & 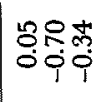 & 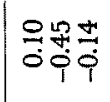 & 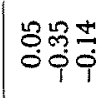 & 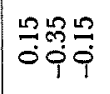 & 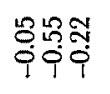 & 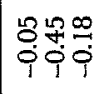 & 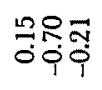 \\
\hline & \begin{tabular}{l|l} 
\\
\multirow{2}{*}{}
\end{tabular} & 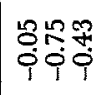 & 윯유 & 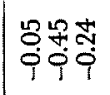 & 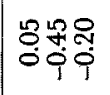 & 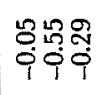 & 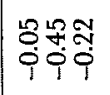 & ơ: \\
\hline & U & 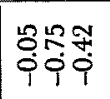 & Oด̆ & \%भo & 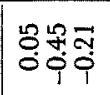 & 뜽ำ & $\begin{array}{l}\text { mo여 } \\
\text { ofíti }\end{array}$ & 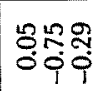 \\
\hline & 90 & 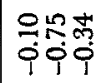 & क्్రి & ㅇ్ధాన్ & 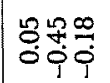 & 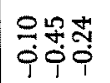 & $\begin{array}{l}\text { mô } \\
\text { poị }\end{array}$ & 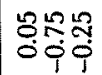 \\
\hline & Uֶ & 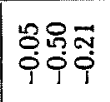 & ค. & 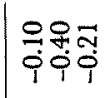 & 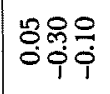 & 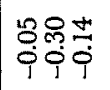 & 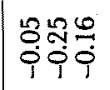 & "1ำ \\
\hline & 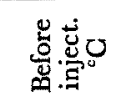 & 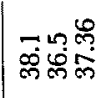 & 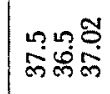 & 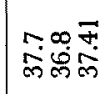 & 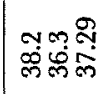 & 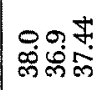 & 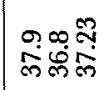 & 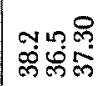 \\
\hline & 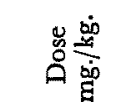 & 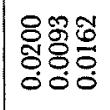 & 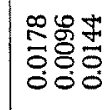 & 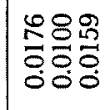 & 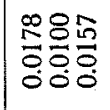 & 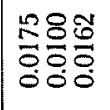 & 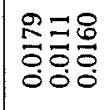 & 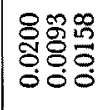 \\
\hline & 言 & స̃ & $\Xi こ \stackrel{\infty}{ \pm}$ & $\mathscr{2}$ & 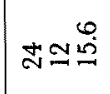 & $\approx=\vec{\alpha}$ & $=\approx \stackrel{\infty}{ \pm}$ & $\approx=\stackrel{2}{2}$ \\
\hline & 总哭 & 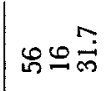 & 的票尔 & 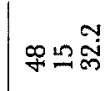 & ৪ুল্ & Rล̊ & และ & உேㄱ \\
\hline & & 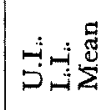 & 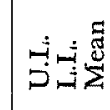 & Н月 & 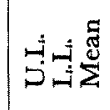 & 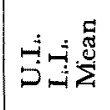 & 势 & 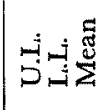 \\
\hline & 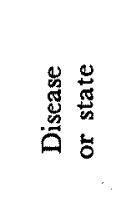 & 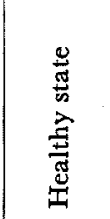 & 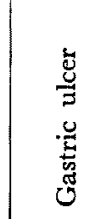 & 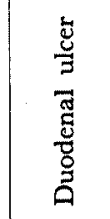 & 点 & 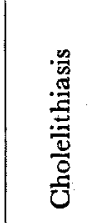 & 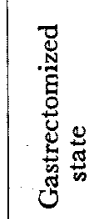 & : \\
\hline
\end{tabular}




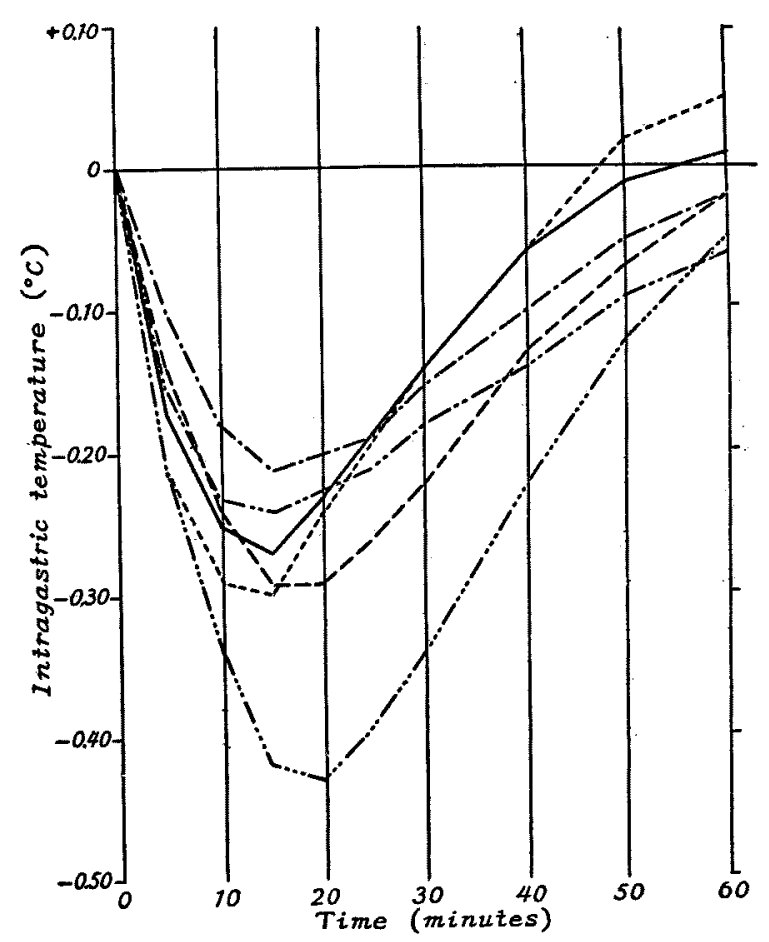

Fig. 1. The changes in the intragastric temperature after the injection of histamine in the groups of gastric (- $\longrightarrow$ ) and duodenal ulcers (- - - ..- ), gastric cancer (-- - - ), cholelithiasis (- - - - ), and gastrectomized (_.....- and healthy states (-.....-

in the pulse pressure represent that the cutaneous blood vessels are dilated and the peripheral resistance is reduced. In addition, by the palpitation and increase in the pulse rate, it is certain that the blood flow increases. Therefore, the blood is cooled down peripherally at the body surface, which is exposed to the lower room temperature $\left(11-24^{\circ} \mathrm{C}\right)$, and returns to the heart. It passes and is probably cooled through the lungs, returns to the heart again, and then flows into the vessels of the stomach. This process is repeated so that the intragastric temperature may fall. This assumption concerning the drop in the intragastric temperature is ascertained by the fact that, as mentioned above, both the onset and the recovery of the drop were preceded by those of the changes in the cardiovascular system, and the curves of these changes were mutually related. The intragastric temperature is in intimate relation with age, as shown in Fig. 2. In general the drop in the intragastric temperature was inversely proportional to the age regardless of the disease-the younger the age, the greater the drop. Next, the gastric free acidity reached the 
Gastrointestinal Temperature. VII

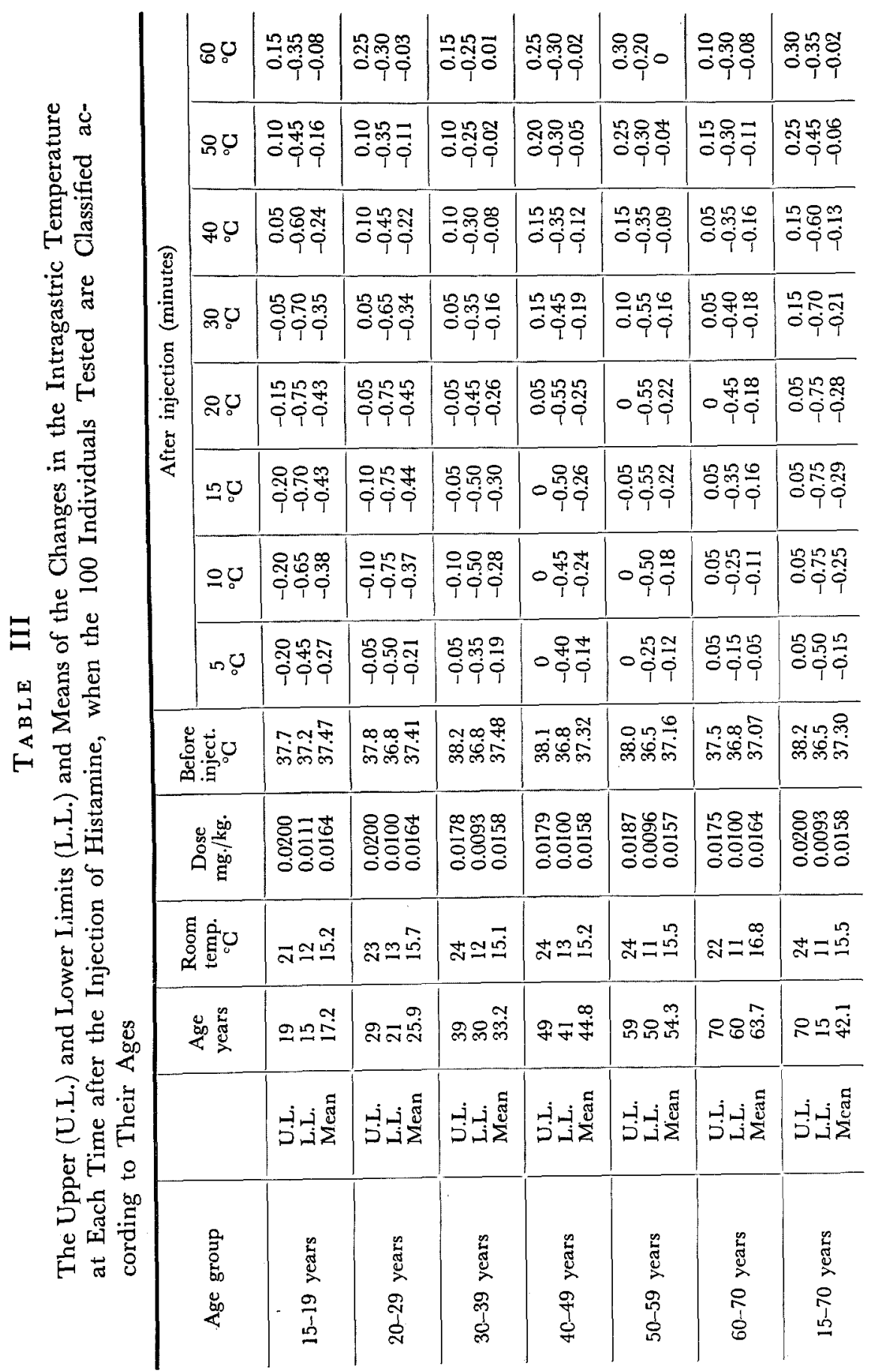




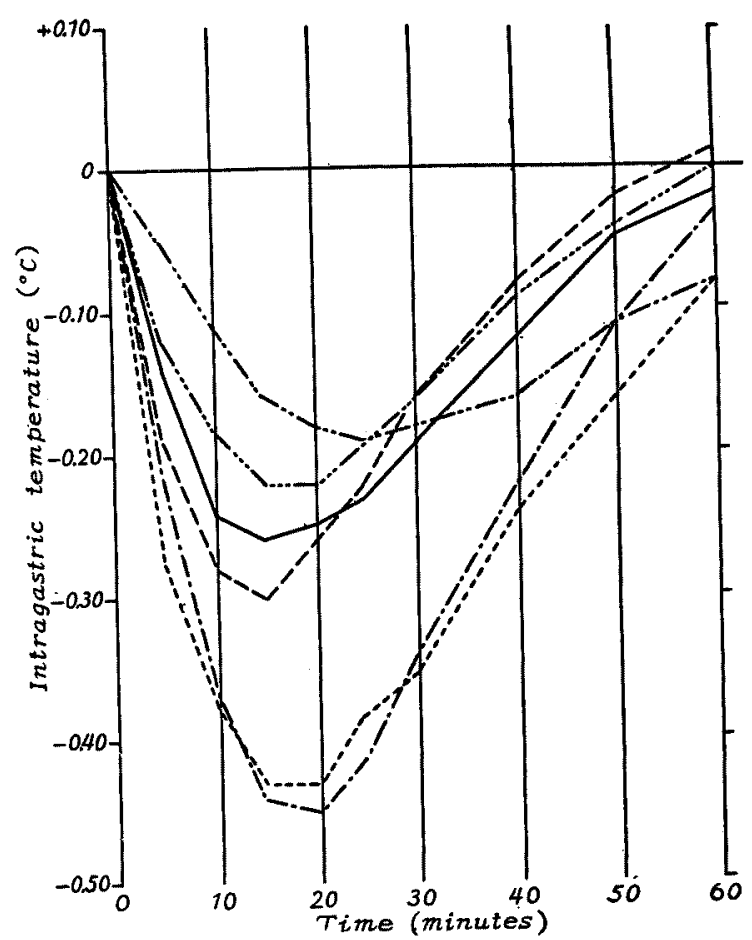

Fig. 2. The changes in the intragastric temperature after the injection of histamine in the various decades (15-19 years: . . . . . . . ; 20-29 years:

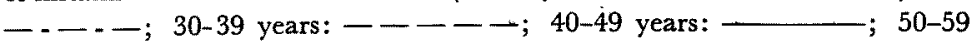
years: $-\ldots \ldots-\ldots$; and $60-70$ years: $\ldots \ldots-. .-$ ).

maximum increase at about 40 minutes after the injection but its increase varied according to the diseases (Fig. 4). As in the group of gastric ulcer, relatively chronic cases were included, the increase in the acidity was not marked. There seems to be no relation between the intragastric temperature and free acidity, because in the case of achylia (cancer etc.) and even in the case in which gastric resection was performed, the intragastric temperature fell as in the other cases, and because no parallelism was noticed between the curves of both changes.

Secondly, correlations among the seven factors, the maximum changes in the intragastric temperature, pulse rate, diastolic blood pressure and gastric free acidity, the age, the injected dose, and the room temperature, are considered to evaluate the relation among them quantitatively. Several simple, partial and multiple correlation coefficients are given in Table IV. The change in the intragastric temperature shows much higher values with those in the pulse rate and diastolic blood pressure than with the other factors in both the simple and the partial correlation coefficients 


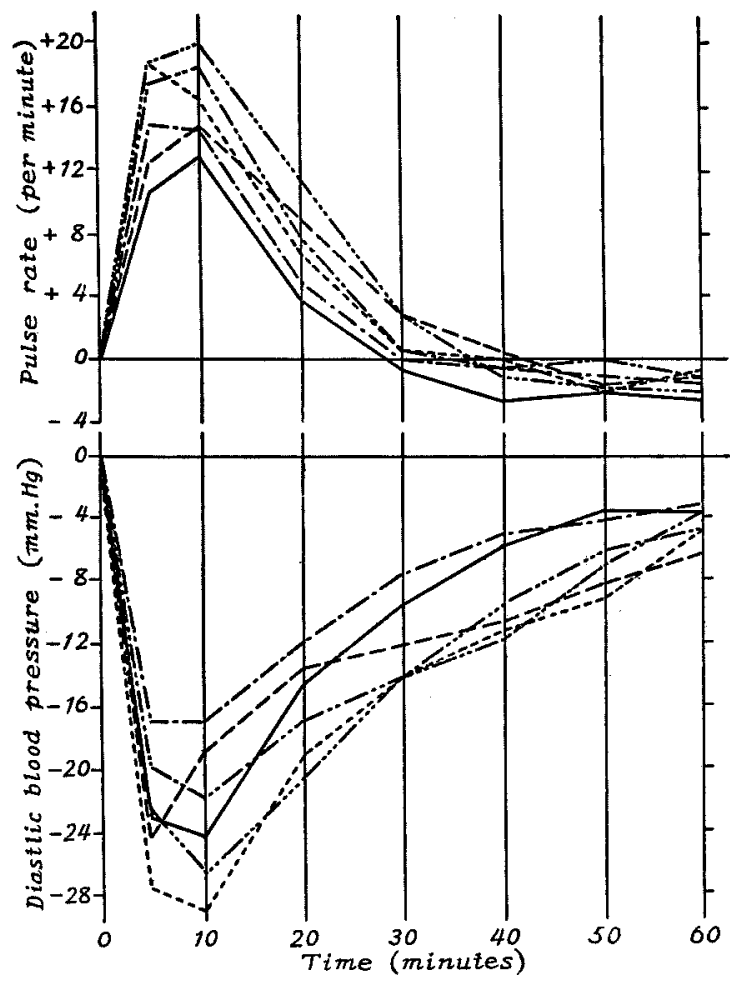

Fig. 3. The changes in the pulse rate and diastolic blood pressure after the injection of histamine as noted in Fig. 1.

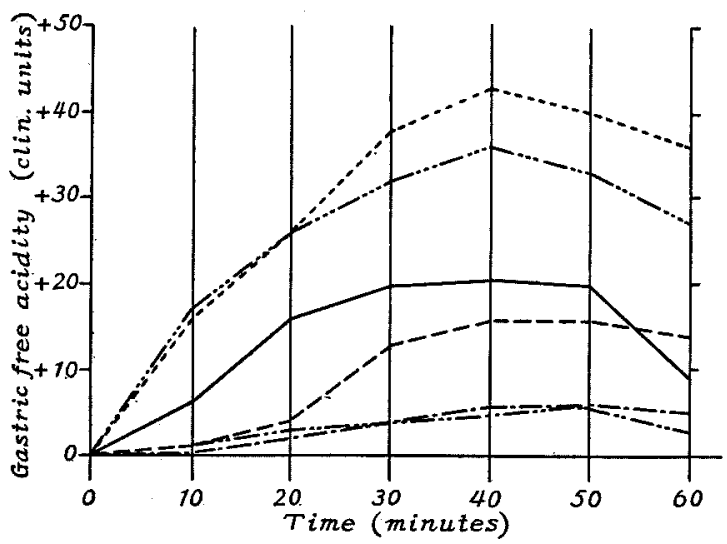

Fig. 4. The changes in the gastric free acidity after the injection of histamine as noted in Fig. 1. 
TAB LE IV

Correlation Coefficients

\begin{tabular}{|c|c|c|c|c|c|c|c|c|c|}
\hline $\mathrm{r}_{\mathrm{TP}}=$ & 0.6076 & $\mathbf{r}_{\mathrm{TD}}$ & $=0.3598$ & $\mathrm{DR}=$ & 0.4890 & $\mathrm{FAR}=$ & 0.0392 & $\mathbf{r}_{\mathrm{T} \cdot \mathrm{PB}}$ & $=0.7536$ \\
\hline $\mathrm{rTB}_{\mathrm{B}}=$ & 0.5931 & $\mathrm{r}_{\mathrm{TR}}$ & $=0.1686$ & $\mathrm{r}_{\mathrm{TB} \cdot \mathrm{PFADR}}=$ & 0.4838 & $\mathrm{r}_{\mathrm{TR} \cdot \mathrm{PBFAD}}=$ & 0.0572 & $\mathbf{r}_{\mathrm{T} \cdot \mathrm{PBA}}$ & $=0.7717$ \\
\hline $\mathbf{r}_{\mathrm{TF}}=$ & 0.2944 & $\mathbf{r}_{\mathrm{TA} \cdot \mathrm{F}}$ & $=-0.2528$ & $\mathrm{r}_{\mathrm{TF}} \cdot \mathrm{PBADR}=$ & 0.1227 & $\mathrm{r}_{\mathrm{FA}-\mathrm{TPBDR}}=$ & $=-0.3925$ & $\mathrm{r}_{\mathrm{T} \cdot \mathrm{PBAD}}$ & $=0.7657$ \\
\hline
\end{tabular}

$\mathrm{T}$ : The maximum drop in the intragastric temperature $\left({ }^{\circ} \mathrm{C}\right)$.

$P$ : The maximum increase in the pulse rate (per minute).

B: The maximum decrease in the diastolic blood pressure (absolute value in $\mathrm{mm}$. $\mathrm{Hg}$ ).

F: The maximum increase in the gastric free acidity (clinical units).

A: The age (years).

D: The injected dose of histamine hydrochloride (mg. per kg.).

$\mathrm{R}$ : The room temperature $\left({ }^{\circ} \mathrm{C}\right)$.

and extends to 0.75 in the multiple correlation coefficient with the formers. Moreover, the latter coefficient does not exceed 0.78, even when the other factors are included. This is coincident with the above described assumption concerning the drop in the intragastric temperature and therefore, from the correlation the assumption is confirmed. The intragastric temperature also shows moderate negative simple correlation with the age, which represents the above stated inverse proportion between them. However, the partial correlation coefficient $\left(\mathrm{r}_{\mathrm{TA} \cdot \mathrm{PB}}\right)$, which is obtained by eliminating the factors of the pulse rate and diastolic blood pressure, becomes much smaller. Accordingly it is certain that the age-factor acts upon the intragastric temperature indirectly through the changes in the pulse rate and blood pressure. The similar tendency with the age is observed in the injected dose, though a weak correlation. Namely, the change in the intragastric temperature is not directly determined by the injected dose. According to the above described assumption concerning the drop in the intragastric temperature, it is expected that the lower the room temperature, the greater the drop becomes. However, there is no correlation between them. The effect of the other factors, for example, the dilatation of the cutaneous vessels, on the process of cooling of blood probably exceeds that of the room temperature. The correlation between the intragastric temperature and systolic blood pressure is smaller than 0.1 and entirely out of question. The partial correlation coefficient between the intragastric temperature and gastric free acidity eliminated the age-factor is not significant, but that between the gastric free acidity and age is significant. Therefore, the gastric free acidity shows no correlation with the intragastric temperature, but negative correlation with the age. Because, as mentioned above, the multiple correlation coefficient of the intragastric temperature with the other (six) factors is about 0.77 , the further factors, which have influence on the 
intragastric temperature, must exist actually. Then it is to be considered whether the disease acts as the factor.

Among the six groups, the patients and the healthy men (Table II), the injected dose and the room temperature showed no significant differences; and as to the age, significant ones were noticed except between healthy state and duodenal ulcer as well as among the remaining four. The intragastric temperature in the healthy men changed most remarkably in comparison with the patients, and its maximum drop was also greatest. Between the groups of duodenal ulcer and healthy state, the changes in the intragastric temperature were significantly different, while no significant differences in the changes in the pulse rate and diastolic blood pressure and in the age were noticed. Furthermore, the same tendency of the changes in the intragastric temperature was seen contrary to the changes in the cardiovascular system respectively in the three combinations: gastric and duodenal ulcers; gastric cancer and gastrectomized state; and healthy state and cholelithiasis. Therefore, it is certain that the disease is one of the factors, which have influence on the intragastric temperature. However, to estimate quantitatively its power and to make clear its mechanism are impossible in the present state of research.

\section{SuMMARY}

Response of the intragastric temperature of men of various age groups, who were in healthy as well as several pathologic states, to subcutaneous injection of histamine was studied, in comparison with changes in the cardiovascular system and gastric juice; and the following facts were confirmed.

1. By histamine the intragastric temperature is lowered following increases in the pulse rate and pulse pressure and a drop in the diastolic blood pressure, which are accompanied by a flush of the face, heat sensation and palpitation.

2. After reaching the maximum drop, it recovers in a manner following the recoveries of the above mentioned changes.

3. It drops on account of flowing of the blood, which is cooled down at the body surface, into the gastric vessels; and the drop is determined chiefly by the changes in the pulse rate and diastolic blood pressure.

4. It is not related with the change in the gastric free acidity.

5. Both age and injected dose of histamine act upon the change in the intragastric temperature indirectly through those in the pulse rate and diastolic blood pressure.

6. Disease is one of the factors which influence the change in the intragastric temperature.

7. Room temperature has no correlation with the change in the 
intragastric temperature.

\section{References}

1) Masuda, Ohara and Katsura, Tohoku J. Exp. Med., 1953, 57, 129.

2) Masuda, Ohara and Katsura, ibid., 1953, 57, 137. 